\title{
Mitigation of Ground Vibration due to Collapse of a Large-Scale Cooling Tower with Novel Application of Materials as Cushions
}

\author{
Feng Lin and Qiheng Zhong \\ Department of Structural Engineering, Tongji University, Shanghai 200092, China \\ Correspondence should be addressed to Feng Lin; lin_feng@tongji.edu.cn
}

Received 18 May 2017; Revised 17 September 2017; Accepted 4 October 2017; Published 25 October 2017

Academic Editor: Mohamed ElGawady

Copyright ( 2017 Feng Lin and Qiheng Zhong. This is an open access article distributed under the Creative Commons Attribution License, which permits unrestricted use, distribution, and reproduction in any medium, provided the original work is properly cited.

\begin{abstract}
Ground vibration induced by the collapse of large-scale cooling towers in nuclear power plants (NPPs) has recently been realized as a potential secondary disaster to adjacent nuclear-related facilities with demands for vibration mitigation. The previous concept to design cooling towers and nuclear-related facilities operating in a containment as isolated components in NPPs is inappropriate in a limited site which is the cases for inland NPPs in China. This paper presents a numerical study on the mitigation of ground vibration in a "cooling tower-soil-containment" system via a novel application of two materials acting as cushions underneath cooling towers, that is, foamed concrete and a "tube assembly." Comprehensive "cooling tower-cushion-soil" models were built with reasonable cushion material models. Computational cases were performed to demonstrate the effect of vibration mitigation using seven earthquake waves. Results found that collapse-induced ground vibrations at a point with a distance of $300 \mathrm{~m}$ were reduced in average by $91 \%, 79 \%$, and $92 \%$ in radial, tangential, and vertical directions when foamed concrete was used, and the vibrations at the same point were reduced by $53 \%, 32 \%$, and 59\% when the "tube assembly" was applied, respectively. Therefore, remarkable vibration mitigation was achieved in both cases to enhance the resilience of the "cooling tower-soil-containment" system against the secondary disaster.
\end{abstract}

\section{Introduction}

A quantity of nuclear power plants (NPPs) will be built in inland China in the next several years to meet the rapidly increasing energy demand [1]. Consequently, cooling towers were planned for construction as indispensable heat rejection devices in inland NPPs. Most of these cooling towers are large-scale and adjacent to a nuclear island due to economic benefit and site limitations. Their heights have usually been designed to be more than $200 \mathrm{~m}$ and the typical spacing to the adjacent nuclear islands is about $300 \mathrm{~m}$ [2]. At present, the highest cooling tower worldwide is $200 \mathrm{~m}$ high and located at Niederaussem, Germany [3]. For safety's sake, it is reasonable to realize that these huge towers may collapse under accidental loads, for example, earthquakes or strong winds far beyond the design level [4]. The collapse of the towers can induce secondary disasters, for example, intensive ground vibrations featured with a mass of uncertain positions of vibratory sources distributing throughout a large area of ground surface. For typical case using strongly weathered sandy slate as foundation soil, the maximum acceleration amplitude of ground vibration in radial direction at a distance of $350 \mathrm{~m}$ can reach as high as $0.29 \mathrm{~g}$ [4]. This will detrimentally affect the safe operation of the close-by nuclear-related facilities and have critical implications of nuclear accidents, as illustrated in Figure 1. However, these risks are not included in the current design concepts of NPPs in which cooling towers and nuclear-related facilities operating in a containment have been designed as fully isolated components $[5,6]$.

Vibration-related potential risks can be appropriately controlled by reducing the ground vibration to a limited level in the framework of a "cooling tower-soil-containment" system. In practice, several measurements are available to reduce impact-induced ground vibration, for example, soft soil acting as a cushion, an isolation trench, and a recipient isolator [7-9]. Among them, the application of soft materials acting as a cushion layer proved to be both efficient and economical under specific circumstances and was widely used in 


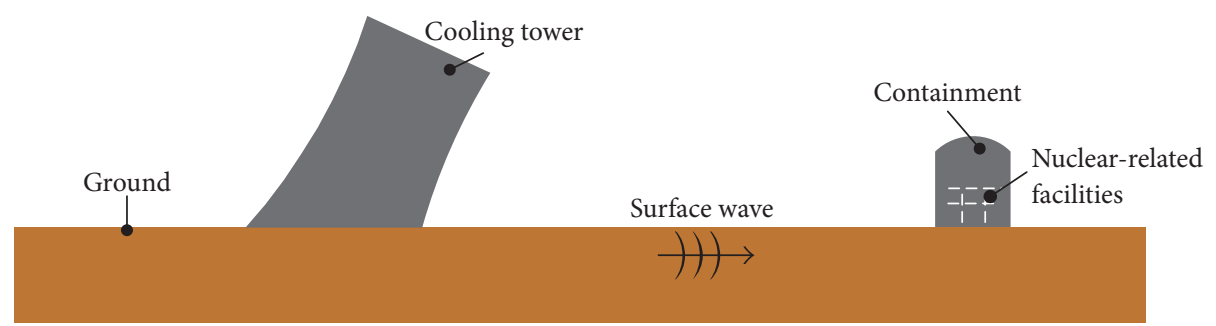

FIGURE 1: Secondary disaster of ground vibration after tower collapse in a "cooling tower-soil-containment" system.

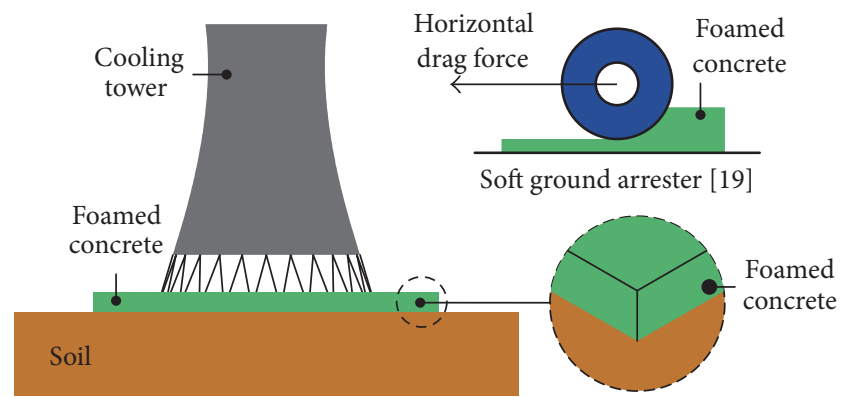

FIGURE 2: Foamed concrete was used as a cushion to reduce ground vibration.

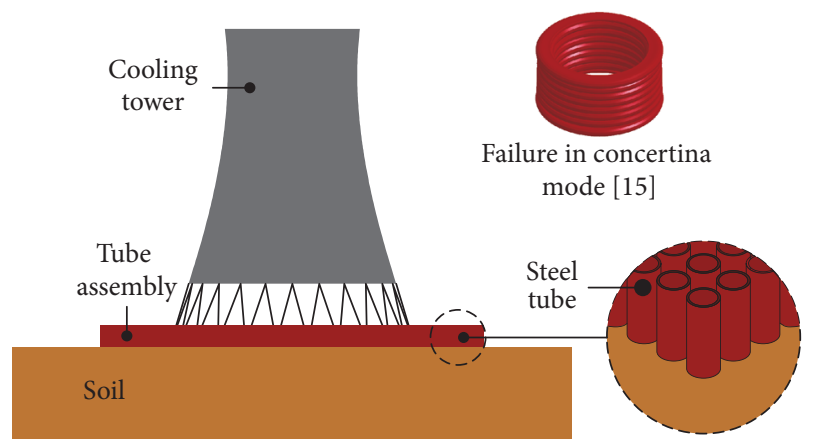

FIGURE 3: "Tube assembly" was used as a cushion to reduce ground vibration.

engineering. For instance, in high-speed railway engineering, rubber bearings were used as resilient elements to reduce train-induced vibrations transmitting to surrounding areas $[10,11]$. In similar scenarios of shelters subjected to rockfall impacts, the dynamic response of the shelters can be significantly reduced when sand cushion or used tire cushion layers were applied $[12,13]$.

To enhance the resilience of the "cooling tower-soilcontainment" system in a disaster scenario, two energy dissipation materials were innovatively applied and acted as a cushion in this study. Figures 2 and 3 illustrate the schematic arrangement of the two materials, that is, foamed concrete and a "tube assembly," which means a mass of thin-walled circular steel tubes were horizontally arranged to form a type of cellular material. Foamed concrete is a kind of porous material and has been used as soft ground arresters for an aircraft overrunning the runway accident [19]. As illustrated in Figure 2, both the leading and trailing wheels were hindered by horizontal drag forces provided by the arrestor bed. Compared to clay, sand, and water, foamed concrete is appropriate for arresting overrunning aircraft due to its stable mechanical properties over a broad range of temperature, negligible crushing-rebounding behavior, durability, and chemically inert composition [20, 21]. On the other hand, thin-walled circular steel tubes could buckle in a form of progressive folds and fail in concertina mode when subjected to uniaxial compression, as illustrated in Figure 3. The crushing behavior of tubes is associated with high energy absorption capacity $[15,22]$. Plastic buckling and the resulting failure modes mainly depend on geometrical parameters, for example, ratios of height to diameter and diameter to thickness. In other words, different geometric parameters can result in failure modes rather than concertina mode, for example, diamond failure mode and Euler failure mode [23]. As far as the authors know, neither material has been used to mitigate impact-related ground vibration in civil infrastructure.

This paper presents a numerical study of novel application of two materials (i.e., foamed concrete and the "tube assembly") acting as cushions to reduce collapse-induced ground. To achieve this, the behavior of the materials was first investigated. Then, numerical approach to build "cooling tower-cushion-soil" models was presented in detail. Using these models, the collapse of a cooling tower was finally simulated and comparative computation was performed to demonstrate ground vibration reduction by using each cushion. In the simulation, the commercial finite element program ANSYS/LS-DYNA was used [24].

\section{Cushion Materials}

The ground vibration reduction closely depends on the properties of the cushion material. In case of a cushion impacted by falling fragments of a collapsed tower, the stressstrain relationship of the cushion material under uniaxial compression is critical because the cushion is dominantly under vertical loads. In this study, proper stress-strain relationships of foamed concrete and the "tube assembly" were obtained based on experimental studies in the literature and trial computations using the models presented in Section 3 to achieve appropriate effect of vibration reduction. Cushion heights were adopted as $4 \mathrm{~m}$ and $2.4 \mathrm{~m}$ for foamed concrete and the "tube assembly," respectively. 


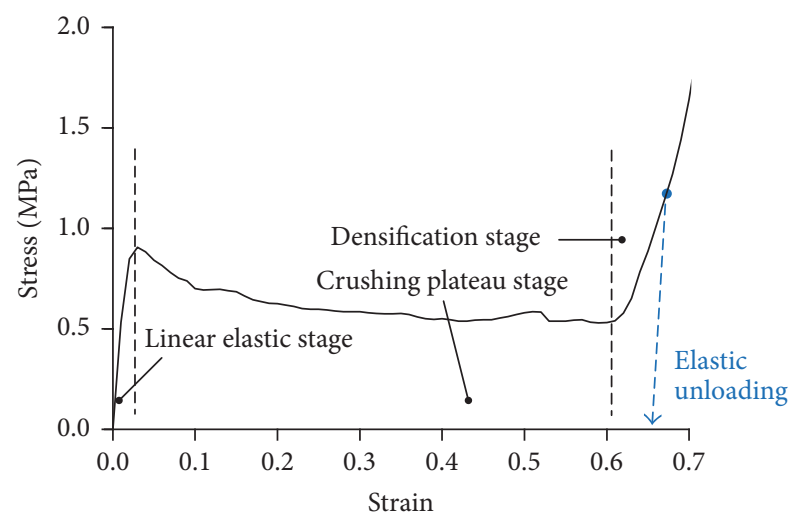

FIGURE 4: Stress-strain curve of foamed concrete under uniaxial compression in tests [14].

2.1. Foamed Concrete. Studies have indicated that the mechanical behavior of foamed concrete under uniaxial compression is primarily dependent on its density and temperature, while being insensitive to strain rate [14]. Foamed concrete with a density of $0.37 \mathrm{~g} / \mathrm{cm}^{3}$ in [14] was chosen for use in this study for vibration mitigation based on trial computations. Figure 4 illustrates the tested stress-strain curves under uniaxial compression, which was chosen for foamed concrete applied in this study. The curve was featured with three stages: the linear elastic stage, crushing plateau stage, and densification stage. The crushing plateau stage is not flat but actually has a negative slope.

A material model with the keyword ${ }^{*}$ MAT CRUSHABLE_FOAM was used, which was provided by the program ANSYS/LS-DYNA and especially applicable to crushable foam-like materials. Poisson's ratio and the damping coefficient of foamed concrete were both set to 0 . Its tensile strength was adopted as $0.3 \mathrm{MPa}$ based on the studies in [25]. Elastic behavior was assumed for unloading.

2.2. Tube Assembly. Different from foamed concrete, experimental data or expressions are presently not available to describe the stress-strain relationship of the "tube assembly" under uniaxial compression. Alternatively, its stressstrain relationship was obtained using a numerical approach including following four steps: (1) confirming the finite element method (FEM) based model of the thin-walled tube presented in [15]; (2) determining the material and dimension of an individual thin-walled tube used in the "tube assembly"; (3) understanding the mechanical behavior of individual thin-walled tube under uniaxial compression using the confirmed FEM model; (4) obtaining the stressstrain relationship of an "equivalent tube" in the form of a hexahedron which was actually used in models in Section 3 for the sake of numerical efficiency.

Step 1 (FEM model in [15]). A FEM-based model for smallscale thin-walled steel tubes under uniaxial compression was developed in [15] and verified using experimental results. The modelling approach was rebuilt by the authors to obtain a
TABLE 1: Material parameters for low carbon steel ST12 [15].

\begin{tabular}{lc}
\hline Parameter & Value \\
\hline Density $\left(\mathrm{g} / \mathrm{mm}^{3}\right)$ & $7.85 \times 10^{-3}$ \\
Elastic modulus $(\mathrm{MPa})$ & $2.1 \times 10^{5}$ \\
Tangent modulus $(\mathrm{MPa})$ & 560 \\
Yield strength $(\mathrm{MPa})$ & 285 \\
Poisson's ratio & 0.3 \\
Parameter $C$ in Cowper-Symonds model $\left(\mathrm{ms}^{-1}\right)$ & 2.6 \\
Parameter $P$ in Cowper-Symonds model & 5.7 \\
\hline
\end{tabular}

reliable numerical tool. Table 1 presents the material properties of low carbon steel ST12 used in [15]. As an example, Figure 5 compares the force-displacement curve simulated by the authors with the experimental results of the circular tube in [15]. It was found that the concertina failure mode was well simulated and both curves featured the folding or sawtooth form. This feature was due to axisymmetric and sequential folding starting at one end of the thin-walled steel tube under uniaxial compression $[15,23]$. In general, the force magnitude in each folding and the amount of folding were well simulated and agreed well with the test data, indicating the efficiency of the FEM model.

Step 2 (material and dimension of individual thin-walled tube used in "tube assembly"). Large-scale thin-walled steel tubes were assumed to construct the "tube assembly" and have the identical material properties to those of low carbon steel ST12 in [15]. Each large-scale tube had an outer diameter of $850 \mathrm{~mm}$, a wall thickness of $20 \mathrm{~mm}$, and a height of $2400 \mathrm{~mm}$. These dimensions were intentionally chosen to have almost identical geometric scales (i.e., ratios of height to diameter and diameter to thickness) to those of circular tubes in [15] to ensure the occurrence of the concertina mode of deformation.

Step 3 (mechanical behavior of individual thin-walled tube under uniaxial compression). The modelling approach in Step 1 was used to build a FEM model for the thin-walled steel tube in Step 2 to understand its mechanical behavior under uniaxial compression. Figure 6 illustrates the FEM model for the thin-walled tube with top and bottom rigid planes. Brick elements (SOLID164) were used to discretize the tube with reduced integration. To control zero energy mode, hourglass control type 4 was adopted with a coefficient set to 0.005 . The tube was meshed into 150 vertical "levels," 160 circumferential "strips," and four "layers" in the thickness direction. This resulted in a maximum mesh size of about $16.0 \mathrm{~mm} \times 16.7 \mathrm{~mm} \times 5.0 \mathrm{~mm}$. The material model with the keyword ${ }^{*}$ MAT_PIECEWISE_LINEAR_PLASTICITY used in Step 1 was also applied for steel with consideration of strain rate effect. The bottom rigid plane was fixed and the top one was movable with constant downward velocities of $0.5 \mathrm{~m} / \mathrm{s}, 20 \mathrm{~m} / \mathrm{s}, 40 \mathrm{~m} / \mathrm{s}$, and $60 \mathrm{~m} / \mathrm{s}$, respectively. These velocities fully covered the velocity range of the fragments which impacted ground after the disintegration of the cooling tower in Section 3. The mass and thickness of 

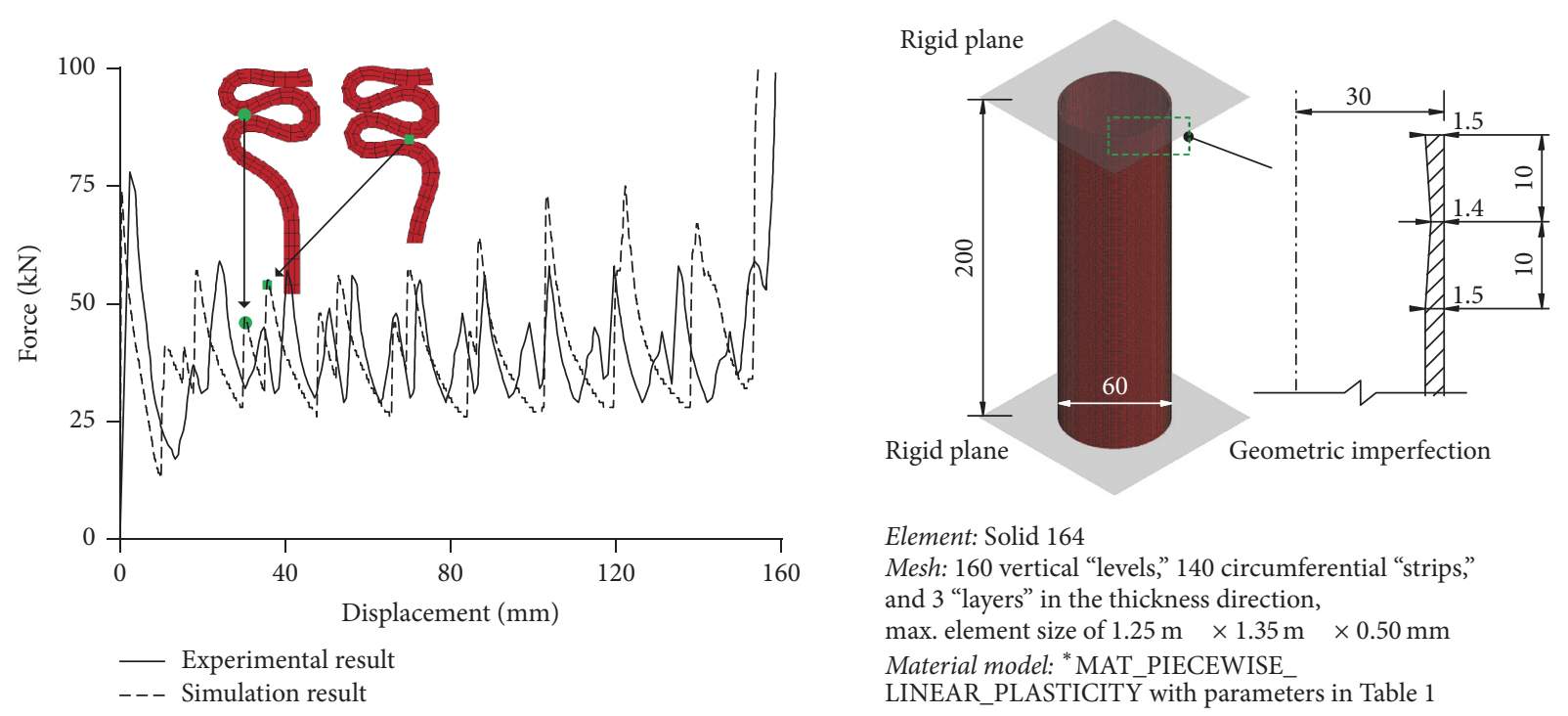

Figure 5: Comparison of force-displacement curve simulated by authors with experimental results of the circular tube in [15].

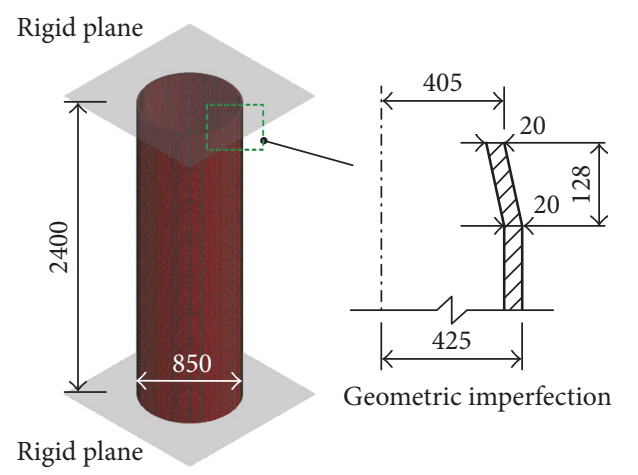

FIGURE 6: FEM model for thin-walled tube.

both planes were negligible. Automatic single surface contact $\left({ }^{*}\right.$ CONTACT_AUTOMATIC_SINGLE_SURFACE) was defined between all the parts with friction coefficient set to 0.3 [15]. Figure 7 presents the force-displacement curves of the thin-walled tube under uniaxial compression at different velocities applied by the top plane. The force was the total response of the bottom plane which was critical for ground vibration in Section 3. Results found a regular fluctuation of the forces with increases in compressive deformation, which is a typical response for a thin-walled steel tube under uniaxial compression [15]. In addition, the forces generally increase with increases in compressive velocities, which was also confirmed in [15].

Step 4 (stress-strain relationship of an "equivalent tube"). It was not rational to directly incorporate the refined FEM model for thin-walled tubes in Step 3 in "cooling towercushion-soil" models established in Section 3, because this resulted in $4.6 \times 10^{9}$ elements of the cushion associated with enormous numerical consumption. Alternatively, a reasonable solution was to construct an "equivalent tube" which had the characteristics of (1) discretization with fewer elements, (2) almost identical mechanical behavior to that of thin-walled tube under uniaxial compression, and (3) almost identical impact-induced ground vibration to that of thinwalled tube.

Figure 8(a) illustrates the profile of the "equivalent tube" in the form of a solid hexahedron with a dimension of $850 \mathrm{~mm} \times 850 \mathrm{~mm} \times 2400 \mathrm{~mm}$. The density of the "equivalent tube" was set to $5.66 \times 10^{-4} \mathrm{~g} / \mathrm{mm}^{3}$ to ensure that the total mass of an "equivalent tube" was identical to that of a thinwalled tube. Figure 8(a) also presents the force-displacement curves for the "equivalent tube" under uniaxial compression at different velocities of $0.5 \mathrm{~m} / \mathrm{s}, 20 \mathrm{~m} / \mathrm{s}, 40 \mathrm{~m} / \mathrm{s}$, and $60 \mathrm{~m} / \mathrm{s}$, respectively. These curves are simplified from those in Figure 7 with consideration of (1) retaining the folding characteristic; (2) approximate amount of the folding; and (3) loading-speed-dependent responses. Based on Figures $8(\mathrm{a})$ and $8(\mathrm{~b})$, the stress-strain curves of the "equivalent tube" under uniaxial compression at different velocities are illustrated.

Impact-induced ground vibrations were compared between the "thin-walled tube-soil" model and "equivalent tube-soil" model, which were illustrated in Figures 9(a) and $9(\mathrm{~b})$, respectively. A rigid plane was set on each tube head with initial downward velocities of $20 \mathrm{~m} / \mathrm{s}, 40 \mathrm{~m} / \mathrm{s}$, and $60 \mathrm{~m} / \mathrm{s}$, respectively. Their tube feet were tied to the soil surface using the keyword *CONTACT_TIED_ SURFACE_TO_SURFACE. The thin-walled tube was modelled using the approach presented in Step 3. The "equivalent tube" was discretized using brick elements with full integration and divided into four elements in vertical direction, resulting in a mesh size of $850 \mathrm{~mm} \times 850 \mathrm{~mm} \times$ $600 \mathrm{~mm}$. The soil model has a dimension of $120 \mathrm{~m} \times 120 \mathrm{~m}$ in plane and $40 \mathrm{~m}$ thickness with its modelling strategy described in Section 3 in detail. As an example, Figure 9(c) 

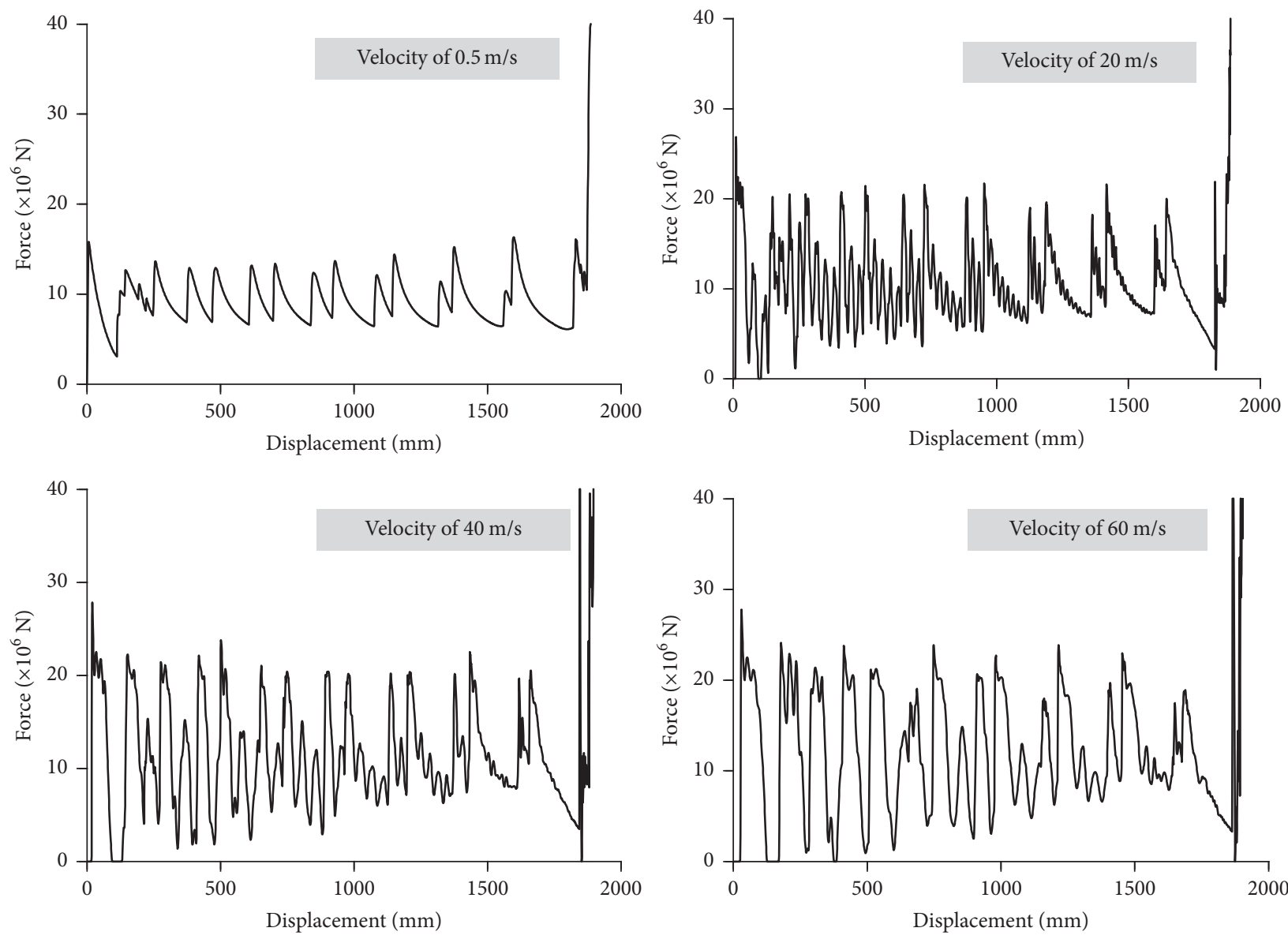

FIgURE 7: Force-displacement curves of thin-walled tube under uniaxial compression at different velocities applied by top plane.
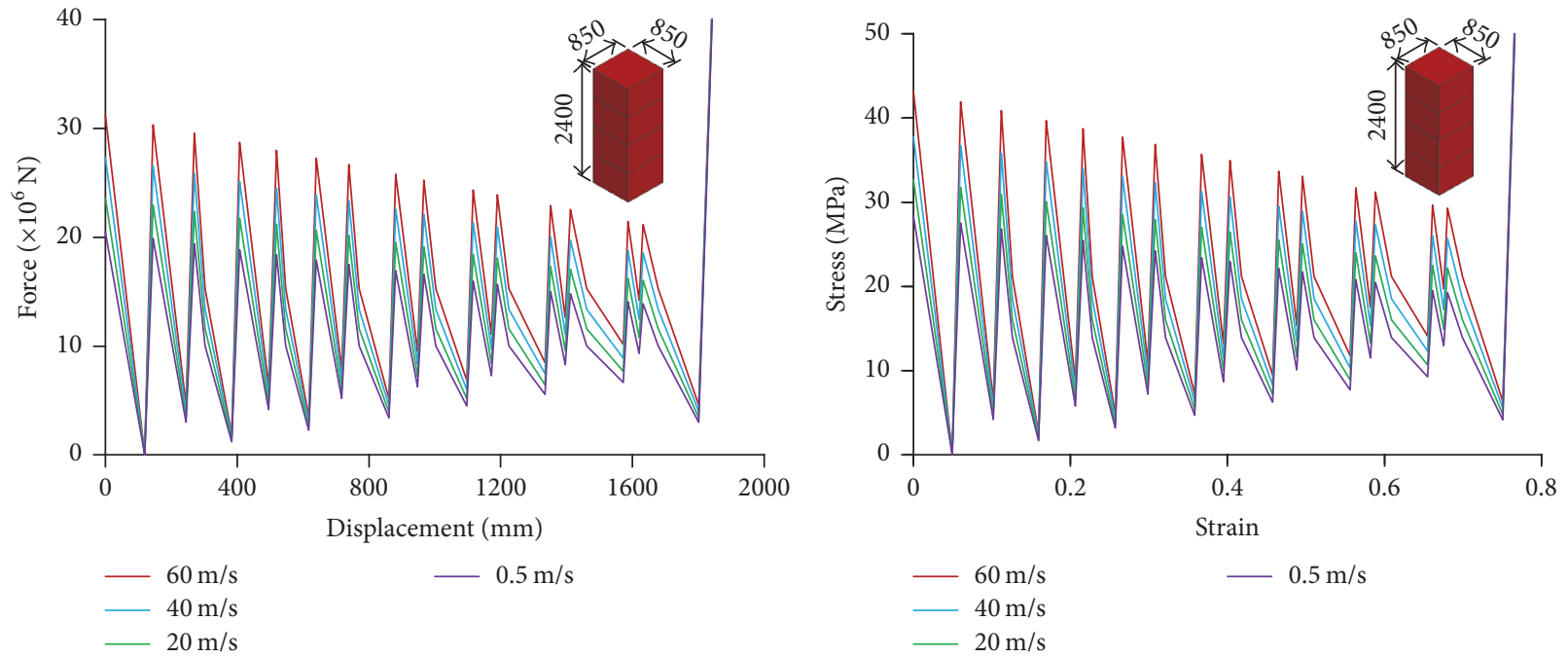

(a)

(b)

FIGURE 8: (a) Force-displacement curves and (b) stress-strain curves of "equivalent tube" under uniaxial compression at different velocities. 


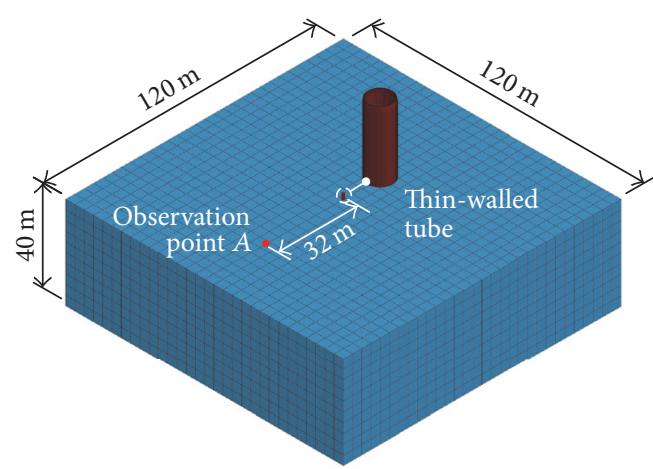

(a)

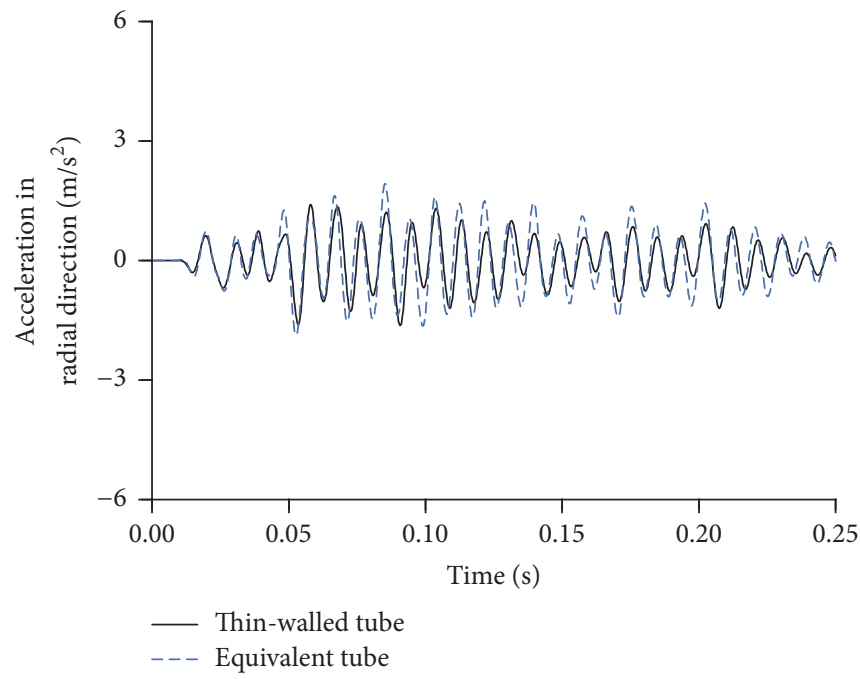

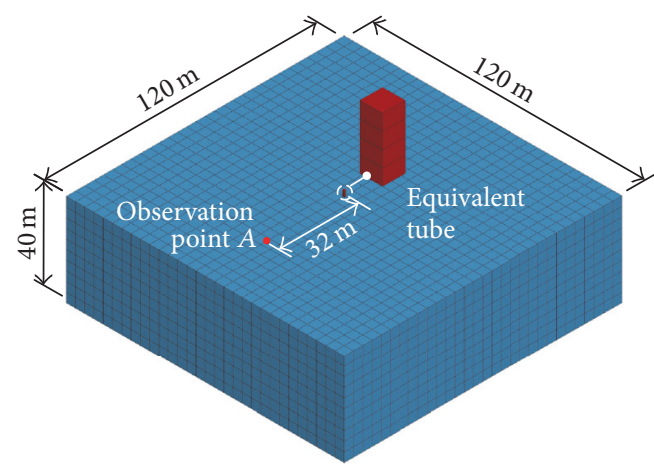

(b)

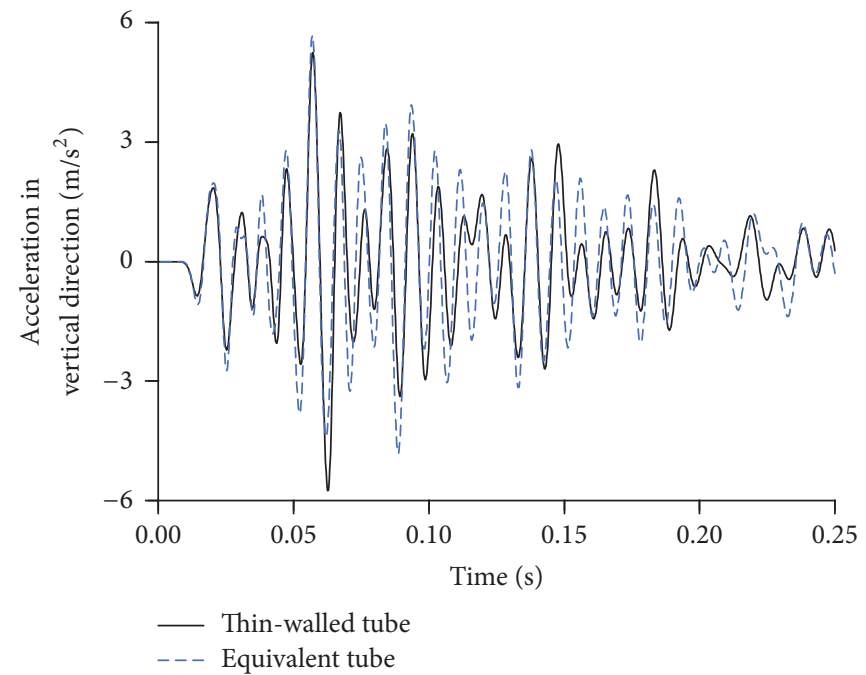

(c)

FIGURE 9: (a) "Thin-walled tube-soil” model; (b) “equivalent tube-soil” model; (c) acceleration histories of observation ground point $A$ at a distance of $32 \mathrm{~m}$ in radial and vertical directions for the case of initial velocity of $60 \mathrm{~m} / \mathrm{s}$.

TABLE 2: Maximum accelerations of observation ground point $A$ in radial and vertical directions at different initial velocities.

\begin{tabular}{|c|c|c|c|c|c|c|}
\hline \multirow{2}{*}{ Number } & \multicolumn{3}{|c|}{ Loading of rigid plane } & \multirow{2}{*}{ Tube type } & \multicolumn{2}{|c|}{ Max. acceleration $\left(\mathrm{m} / \mathrm{s}^{2}\right)$} \\
\hline & Velocity $(\mathrm{m} / \mathrm{s})$ & Kinetic energy $(\mathrm{J})$ & Mass $(\mathrm{kg})$ & & Radial & Vertical \\
\hline \multirow{2}{*}{1} & \multirow{2}{*}{20} & \multirow{2}{*}{$1.80 \times 10^{7}$} & \multirow{2}{*}{$9.00 \times 10^{4}$} & Thin-walled tube & 1.49 & 4.20 \\
\hline & & & & Equivalent tube & 1.49 & 4.20 \\
\hline \multirow{2}{*}{2} & \multirow{2}{*}{40} & \multirow{2}{*}{$1.80 \times 10^{7}$} & \multirow{2}{*}{$2.25 \times 10^{4}$} & Thin-walled tube & 1.87 & 4.96 \\
\hline & & & & Equivalent tube & 1.56 & 4.73 \\
\hline \multirow{2}{*}{3} & \multirow{2}{*}{60} & \multirow{2}{*}{$1.80 \times 10^{7}$} & \multirow{2}{*}{$1.00 \times 10^{4}$} & Thin-walled tube & 1.63 & 5.75 \\
\hline & & & & Equivalent tube & 1.93 & 5.68 \\
\hline
\end{tabular}

illustrates the computed acceleration histories of observation ground point $A$ at a distance of $32 \mathrm{~m}$ in radial and vertical directions for the case of initial velocity of $60 \mathrm{~m} / \mathrm{s}$. Table 2 presents the maximum acceleration of point $A$ in radial and vertical directions at different loading velocities. Ground acceleration in tangential direction was too small due to central symmetry and thereby ignored. Results found that similar ground vibrations were achieved using the "thin-walled tube-soil" model and "equivalent tube-soil" model which meant that the "equivalent tubes" could be incorporated in the "cooling tower-cushion-soil" model in Section 3 to replace the thin-walled tubes.

\section{3. "Cooling Tower-Cushion-Soil" Model}

3.1. Computational Cases. Three computational cases illustrated in Figure 10 were conducted to compare the vibration reduction by using two materials acting as cushions. Case 1 contained a cooling tower and homogeneous soil with finite dimension to provide a baseline of ground vibration. 


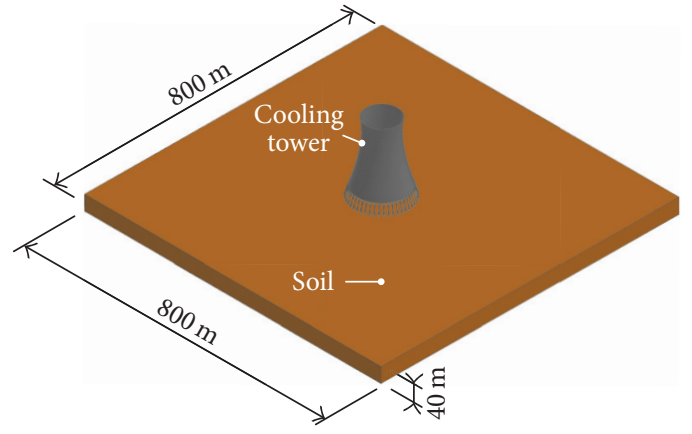

(a)

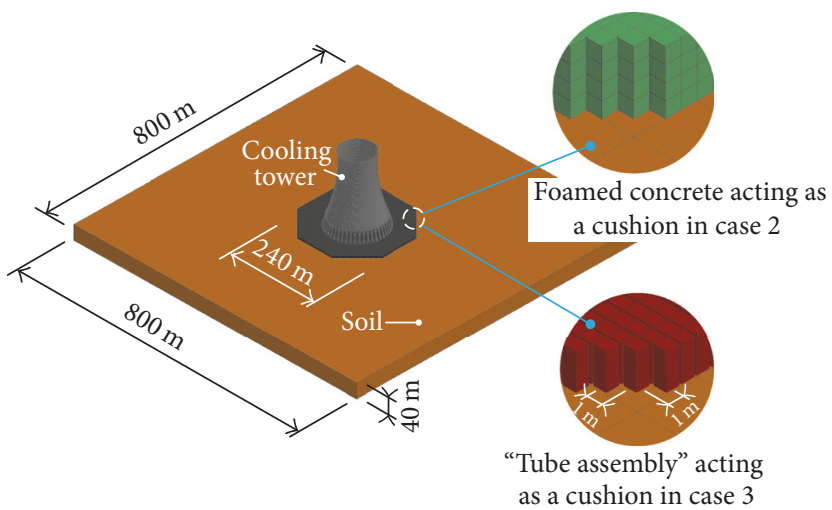

(b)

Figure 10: (a) Model for computational Case 1; (b) models for computational Cases 2 and 3.

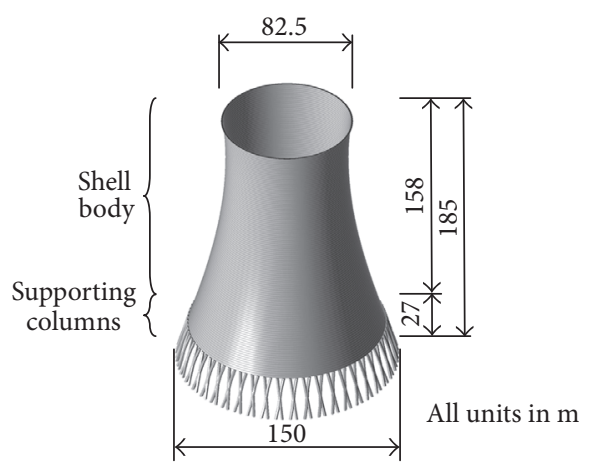

Tower Information

Geometry: shell thickness: $0.3 \sim 1.8 \mathrm{~m}$ Column: 48 pairs, $1.8 \mathrm{~m}$ in diameter

Reinforcement: circumferential inner side: 0.13 0.74\%

Circumferential outer side: $0.16 \sim 1.02 \%$

Meridional inner side: 0.16 0.91\%

Meridional outer side: $0.18 \sim 1.00 \%$

Material: concrete: elastic modulus: $3.25 \times 10^{4} \mathrm{MPa}$

Compressive strength: $27 \mathrm{MPa}$

Tensile strength: $2.4 \mathrm{MPa}$

Rebar: elastic modulus: $2.1 \times 10^{5} \mathrm{MPa}$

Tangent modulus: $2.1 \times 10^{3} \mathrm{MPa}$

Yield strength: $345 \mathrm{MPa}$

FIgURE 11: Profile of the cooling tower.

No cushion was used in Case 1 , while in Cases 2 and 3 foamed concrete and the "tube assembly" were applied as cushion material, respectively. These models did not contain the modelling of nuclear-related facilities and a containment. Actually, a big model to describe the behavior of the integral "cooling tower-soil-containment" system could be built without technical difficulty, however, at the cost of enormous numerical consumption. Alternatively, the containment including nuclear-related facilities could be separately modelled using the ground vibration obtained from "cooling tower-cushion-soil" model as input data with less computational cost. This was beyond the study scope and not demonstrated in this paper.

Figure 11 illustrates the dimension and material parameters of a reinforced concrete cooling tower. The cooling tower was excerpted from a practical project as described in [26] at the Jidong Nuclear Power Station with a height of $185 \mathrm{~m}$ including a shell body and supporting columns. The cushions of foamed concrete and the "tube assembly," with a height of $4 \mathrm{~m}$ and $2.4 \mathrm{~m}$, respectively, were both in the planar form of an octagon with an in-circle radius of $120 \mathrm{~m}$. The choice of the planar size was based on the debris area in the collapse simulation of the cooling tower. Foamed concrete was homogeneously constructed to build the cushion and lateral deformation was generally negligible for foamed concrete under uniaxial compression [27]. However, for the cushion
TABLE 3: Soil parameters.

\begin{tabular}{lc}
\hline Parameter & Value \\
\hline Density $\left(\mathrm{g} / \mathrm{mm}^{3}\right)$ & $2.5 \times 10^{-3}$ \\
Dynamic shear modulus $(\mathrm{MPa})$ & 5150 \\
Poisson's ratio & 0.33 \\
Internal friction angle $(\mathrm{rad})$ & 0.64 \\
Cohesion $(\mathrm{MPa})$ & 1.64 \\
Damping ratio $(\%)$ & 1.50 \\
\hline
\end{tabular}

of the "tube assembly," the thin-walled circular tubes with each diameter of $0.85 \mathrm{~m}$ were independently arranged with a center-to-center spacing of $1 \mathrm{~m}$, resulting in a minimum gap of $0.15 \mathrm{~m}$ between two neighboring tubes, as illustrated in Figure 10. This gap was intentionally reserved so that (1) the folds of a tube under uniaxial compression could freely form without lateral restraint caused by neighboring tubes; thus, (2) the uniaxial compression state of "equivalent tubes" was properly achieved in numerical simulation. The soil belonged to the commonly used moderately weathered sandy slate [28]. Soil parameters are presented in Table 3.

3.2. Modelling. Two "cooling tower-cushion-soil" models were developed for Cases 2 and 3, respectively, based on a 
TABLE 4: Brief description of "cooling tower-soil" model $[2,4,8]$.

\begin{tabular}{|c|c|c|c|c|}
\hline Region & Element & Material model & Meshing & Remark \\
\hline Tower shell & SHELL163 & Material models in Eurocode 2 Part 2.1 & $\begin{array}{c}108 \text { vertical "levels" and } 384 \\
\text { meridional "strips," max. size of } \\
1.2 \mathrm{~m} \times 1.5 \mathrm{~m}\end{array}$ & $\begin{array}{l}\text { Proper technique was used to } \\
\text { connect shell elements in tower } \\
\text { shell and solid elements in } \\
\text { columns }\end{array}$ \\
\hline \multicolumn{5}{|l|}{ Column } \\
\hline Concrete & SOLID164 & Holmquist-Johnson-Cook model & $\begin{array}{l}26 \text { vertical "levels" and } 4 \\
\text { elements in each "levels," max. } \\
\text { size of } 0.6 \mathrm{~m} \times 1.0 \mathrm{~m} \times 1.3 \mathrm{~m}\end{array}$ & $\begin{array}{l}\text { Perfect bond between concrete } \\
\text { and rebars }\end{array}$ \\
\hline Rebar & BEAM161 & Plastic kinematic model & Max. size of $1.3 \mathrm{~m}$ & \\
\hline Soil & SOLID164 & Drucker-Prager model & $\begin{array}{l}\text { Sizes of } 4 \mathrm{~m} \times 4 \mathrm{~m} \times 4 \mathrm{~m} \text { were } \\
\text { meshed in soil model with a } \\
\text { dimension of } 800 \mathrm{~m} \times 800 \mathrm{~m} \\
\text { (plane) } \times 40 \mathrm{~m} \text { (thickness) }\end{array}$ & $\begin{array}{c}\text { Nonreflecting boundaries and } \\
\text { damping were set in the soil } \\
\text { model }\end{array}$ \\
\hline
\end{tabular}

"cooling tower-soil" model which was applicable to Case 1. Previously, the "cooling tower-soil" model was established by the first author and his collaborators to predict the collapseinduced ground vibration using the program ANSYS/LSDYNA [2, 4, 8]. Table 4 briefly describes the modelling approach for the cooling tower and soil, and more details can be found in $[2,4,8]$. For modelling the cushion of foamed concrete, brick elements with full integration were used to achieve numerical stability with a mesh size of $1 \mathrm{~m} \times 1 \mathrm{~m} \times 1 \mathrm{~m}$. The material model used in Section 2.1 was also applied. For modelling the cushion of the "tube assembly," 47660 "equivalent tubes" were arranged with each dimension of $0.85 \mathrm{~m} \times 0.85 \mathrm{~m} \times 2.4 \mathrm{~m}$ and separated from each other with a center-to-center spacing of $1.0 \mathrm{~m}$. The modelling approach was identical to that presented in Step 4 in Section 2.2. Poisson's ratio of "equivalent tube" was set to 0 . Each cushion was appropriately connected to the soil ( ${ }^{*}$ CONTACT_TIED_SURFACE_TO_SURFACE).

Several considerations were also addressed to make the calculation reasonable and efficient $[2,4,8]$. First, the column feet were numerically separated from the soil surface. By doing this, the earthquake wave was input at the element nodes on column feet. Second, collisions acted among shell fragments as well as between a shell fragment and soil during the collapse process. To simulate these, the commonly used penalty function method was used. The parameters were calibrated using impact test results of concrete blocks [29]. Third, for each tube, the top nodes were constrained ( ${ }^{*}$ CONSTRAINED_NODE_SET\&* ${ }^{*}$ BOUNDARY_SPC_SET) so that they move simultaneously only in vertical direction. Fourth, reduced integration was applied in solid elements in the tower column and in the soil model to make the computation efficient, however, accompanied by undesired zero energy modes. To appropriately control these modes, hourglass control type 4 was applied. Finally, in a FEM-based dynamic analysis of wave propagation, the maximum mesh size of the soil model, $l_{e}$, should fit the following Eq. (1) [30]:

$$
l_{e} \leq\left(\frac{1}{12} \sim \frac{1}{6}\right) \cdot \lambda_{T}=\left(\frac{1}{12} \sim \frac{1}{6}\right) \cdot \frac{v}{f_{T}}
$$

where $\lambda_{T}$ is the wave length corresponding to the dominant wave frequency, $f_{T} ; v$ denotes the propagation velocity of the wave under consideration.

Seven ground motion waves were individually used to cause the cooling tower to collapse and investigate the ground vibration. One of these waves was an artificial earthquake wave that is commonly used in nuclear engineering for seismic design in China. This earthquake wave matched the standard RG1.60 response spectrum proposed by the US Atomic Energy Commission [16] and was denoted as earthquake wave RG1.60 in this study. Figure 12 presents the acceleration history of the earthquake wave RG1.60 in two horizontal directions ( $X$ and $Y$ ) and vertical direction $(Z)$ with the PGA normalized to $1.0 \mathrm{~g}$. Other six earthquake waves were obtained from the Pacific Earthquake Engineering Research Center [31] with consideration of the soil properties commonly used in NPPs, that is, Coyote Lake (Gilroy Array \#1 station), Kobe (Kobe University station), Loma Prieta (Gilroy Array \#1 station), Northridge (LA Dam station), San Fernando (Pacoima Dam station), and Whittier Narrows (LA-Wonderland Ave station). The peak ground acceleration (PGA) of these earthquake waves in two horizontal directions and in the vertical directions was first set to $0.3 \mathrm{~g}, 0.3 \mathrm{~g}$, and $0.2 \mathrm{~g}$ (g denotes the acceleration of gravity), respectively. The resulting ratio $0.3: 0.3: 0.2=1: 1: 0.67$ was in agreement with the code GB 50267-97 [28]. Each earthquake wave was input on the bottom nodes of the elements on the column feet to shake the cooling tower model. Eventually, incremental inputs were performed gradually with a fixed step increment for PGAs of $0.1 \mathrm{~g}$ in two horizontal directions and $0.067 \mathrm{~g}$ in the vertical direction until the tower collapsed. In the computation, central difference method was used to solve the dynamic equations with time step controlled by the program and the maximum value of time step being $4 \times 10^{-5} \mathrm{~s}$.

3.3. Model Verification. The "cooling tower-soil" model was verified in several aspects, including (1) the collapse process analysis of a cooling tower model in a column failure test [32] and in a shaking table test [33]; and (2) the in situ monitoring of ground vibration caused by falling weight [8]. In addition, an on-site monitoring of ground vibration induced by the 

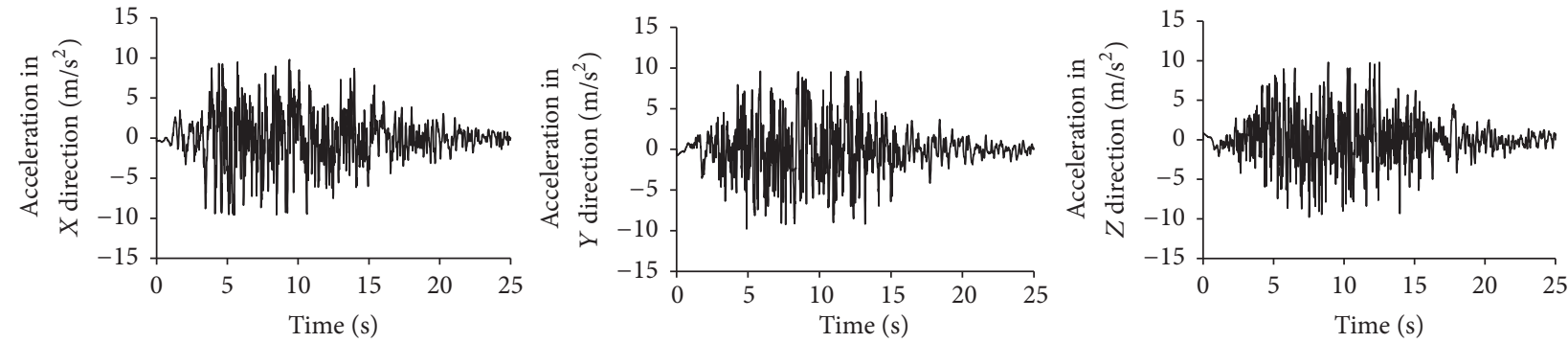

FIGURE 12: Artificial earthquake wave in accordance with RG1.60 response spectrum [16].

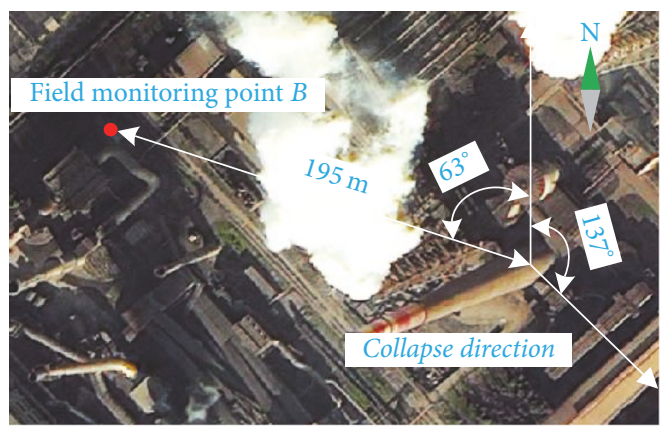

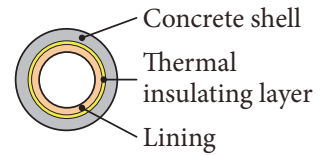

Composition of the chimney shell in transverse cross sections

\begin{tabular}{ccccc}
\multicolumn{5}{c}{ Chimney dimension } \\
$\begin{array}{c}\text { Height } \\
(\mathrm{m})\end{array}$ & $\begin{array}{c}\text { Outer } \\
\text { radius } \\
(\mathrm{mm})\end{array}$ & $\begin{array}{c}\text { Concrete } \\
\text { shell }\end{array}$ & $\begin{array}{c}\text { Thickness }(\mathrm{mm}) \\
\text { Thermal } \\
\text { insulating layer }\end{array}$ & Lining \\
\hline 0 & 9700 & 700 & 80 & 240 \\
30 & 8500 & 500 & 80 & 240 \\
50 & 7700 & 500 & 80 & 120 \\
70 & 7100 & 400 & 80 & 120 \\
110 & 5900 & 300 & 80 & 120 \\
160 & 4600 & 200 & 80 & 120 \\
200 & 3600 & 400 & 80 & 120 \\
\hline
\end{tabular}

Figure 13: Profile of the chimney and the position of ground point $B$ where ground vibration was measured [17].
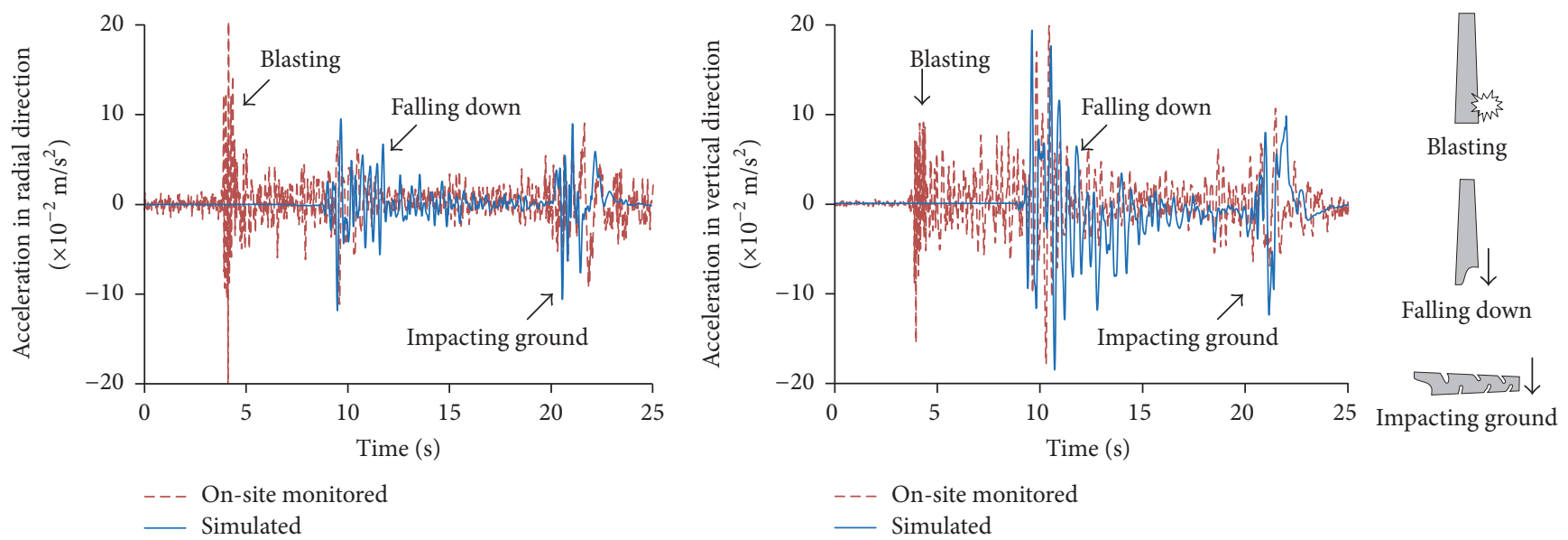

FIGURE 14: On-site monitored and simulated acceleration history of ground vibration at point $B$ in radial and vertical directions [18].

demolition of a reinforced concrete chimney was recently performed by the first author and his collaborators and used herein for model verification [18]. The chimney, located in Shanghai, China, was $200 \mathrm{~m}$ high and demolished by controlled blasting. A "chimney-soil" model was built to predict the ground vibration using the identical modelling approach in the "cooling tower-soil" model. Figure 13 presents the bird's eye view of the chimney, the chimney dimension, and the position of ground point $B$ where ground vibration was monitored [17]. The uniaxial compressive strength of concrete was $23.4 \mathrm{MPa}$ and the yield strength of the reinforcing steel bars was $400 \mathrm{MPa}$. The reinforcement ratios in the inner and outer sides in circumferential direction were $0.31 \%-1.1 \%$ and $1.1 \%-3.3 \%$, respectively. Those in meridional direction were $0.33 \%-1.3 \%$ and $1.1 \%-2.4 \%$, respectively. The soil density, shear wave velocity, dynamic shear modulus, Poisson's ratio, cohesion, and internal friction angle were $2200 \mathrm{~kg} / \mathrm{m}^{3}, 244 \mathrm{~m} / \mathrm{s}, 190 \mathrm{MPa}, 0.33,1.64 \mathrm{MPa}$, and $36.42^{\circ}$, respectively. The chimney was meshed using 64 "levels" in vertical direction and 157 "strips" in meridional direction, resulting in total of 9678 shell elements. The soil model with a dimension of $600 \mathrm{~m} \times 600 \mathrm{~m} \times 35 \mathrm{~m}$ was discretized using 20000 solid elements. The elements actually destroyed by blasting were numerically achieved by a "killing" technique provided by the program ANSYS/LS-DYNA. Figure 14 compares the on-site monitored and simulated acceleration histories of ground vibration at point $B$. Table 5 presents the on-site monitored and simulated acceleration amplitudes of 
TABLE 5: Comparison of the on-site measured and simulated maximum acceleration amplitudes of ground vibration at point $B^{*}$ [18].

\begin{tabular}{lcccc}
\hline \multirow{2}{*}{ Direction } & Stage & & Amplitude $\left(\times 10^{-2} \mathrm{~m}^{2} \mathrm{~s}^{2}\right)$ \\
& & On-site monitored & 19.65 & Error $^{\#}$ \\
\hline \multirow{2}{*}{ Vertical } & Falling down & 19.10 & 9.93 & $2.88 \%$ \\
& Impacting ground & 10.19 & -11.16 & $2.55 \%$ \\
\multirow{2}{*}{ Radial } & Falling down & -10.92 & 9.00 & $-0.67 \%$ \\
& Impacting ground & 9.06 & 9.00 \\
\hline
\end{tabular}

${ }^{*}$ The position of field monitoring point $B$ was indicated in Figure 13. ${ }^{*}$ Error $=($ simulated value - on-site monitored value $)$ /on-site monitored value.
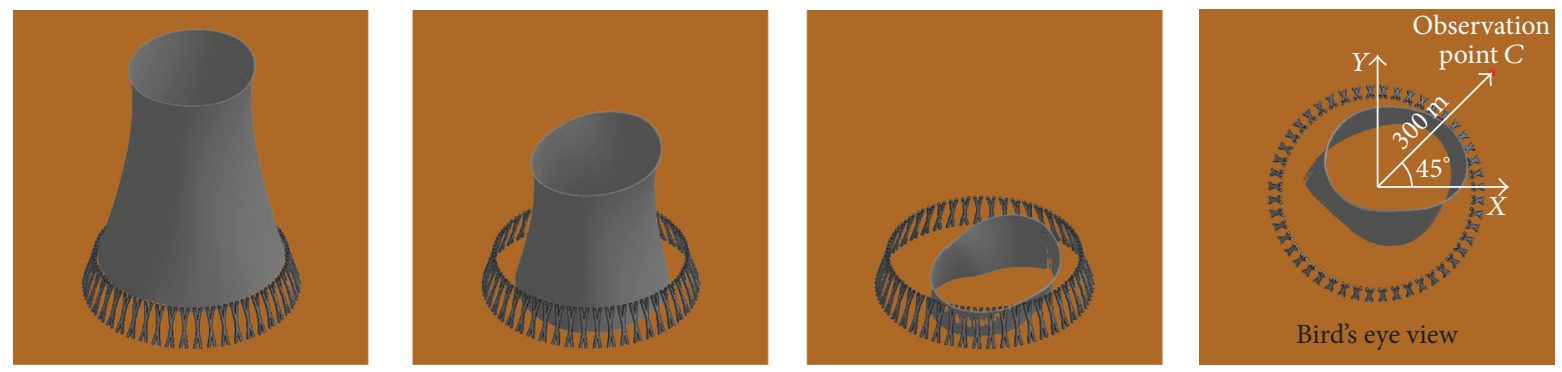

FIGURE 15: Collapse process of the cooling tower under the earthquake wave RG1.60.

ground vibration at point $B$. Results found that the vibration in the "falling down" and "impacting ground" stages was well predicted with the maximum error of acceleration amplitudes in a range from $-2.55 \%$ to $2.88 \%$. However, the comparison on the vibration in "blasting" stage was unavailable because the blasting effect was not simulated.

\section{Vibration Mitigation}

4.1. Collapse of Cooling Tower. The cooling tower survived until a certain PGA of an individual earthquake was reached. As an example, Figure 15 illustrates the collapse process of the cooling tower under the earthquake wave RG1.60 featured with the collapse mode of "collapse in integrity" [8]. A dominant collapse direction and point $C$ at a distance of $300 \mathrm{~m}$ for observing ground vibration are also indicated in Figure 15.

4.2. Vibration Mitigation Effect. Figure 16 illustrates the acceleration histories of collapse-induced ground vibrations at point $C$ in radial, tangential, and vertical directions in Cases 1, 2, and 3 for the cooling tower under the earthquake wave RG1.60. Table 6 compares the maximum acceleration amplitudes in radial, tangential, and vertical directions at different distances in Cases 1, 2, and 3 for the cooling tower under seven earthquake waves. In the computation, individual dominant collapse direction for the collapse of the cooling tower under each earthquake wave was used when evaluating ground vibration. Results found that collapseinduced ground vibration was remarkably reduced using each cushion. For the observation point $C$ with a distance of $300 \mathrm{~m}$, which is typical spacing between a cooling tower and adjacent nuclear island in China, the averaged maximum acceleration amplitudes were reduced by $91 \%, 79 \%$, and $92 \%$ in radial, tangential, and vertical directions in Case 2 and 53\%, 32\%, and $59 \%$ for those in Case 3, respectively. Evidently, in the concerned cases, foamed concrete was more effective than the "tube assembly." In addition, the vibration reduction became weak with increases in distances.

4.3. Discussion. Three issues are discussed in this subsection, that is, mitigation effect of ground vibration, cushion heights, and comparison of mitigation effect with those in previous studies. The different mitigation effects are attributed to related physical properties (e.g., strength and deformability) and associated dynamic responses of the cushions (e.g., compaction height and energy absorption). Firstly, as illustrated in Figures 4 and 8(b), the strength of foamed concrete averaged about $0.61 \mathrm{MPa}$ and the corresponding values approximately ranged from 13.6 to $20.8 \mathrm{MPa}$ for the "equivalent tube" at different loading velocities. Both cushions had an ultimate strain of about 0.7. In appropriate conditions, a "soft" cushion (e.g., foamed concrete) commonly resulted in a better mitigation effect than a "hard" cushion (e.g., "tube assembly") did. This has been generally accepted in engineering practice and was confirmed in [4]. In other words, the mitigation effect of two cushions will be similar if their related physical properties (e.g., strength and deformability) are comparable. However, detailed studies are beyond the scope of this study. Secondly and consequently, compaction heights of two cushions compressed by fallen shell fragments were significantly different. Figure 17 illustrates the distribution of compaction heights of two cushions for the cooling tower under the earthquake wave RG1.60. Foamed concrete with a height of $4 \mathrm{~m}$ was maximumly compacted by about $3.80 \mathrm{~m}$ which meant that the foamed concrete was almost fully compressed in the densification stage in certain places. However, the "tube assembly" was maximumly compacted by about $0.61 \mathrm{~m}$ which was remarkably less than the compaction height of the foamed concrete of $3.80 \mathrm{~m}$. Thirdly, the energy 

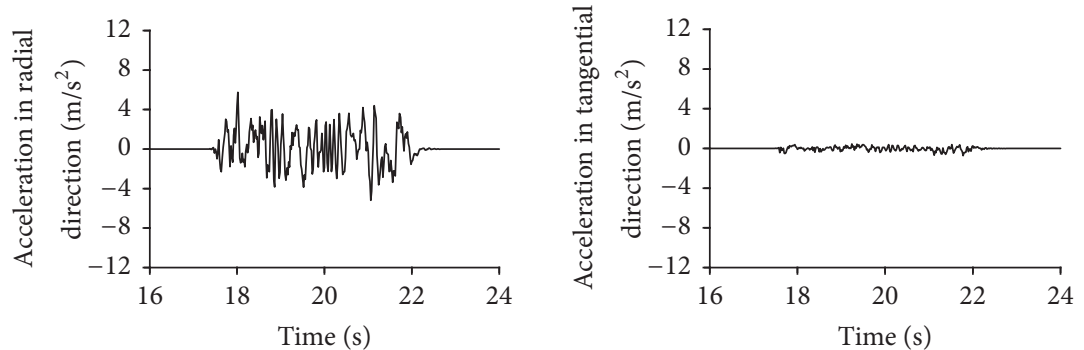

(a)
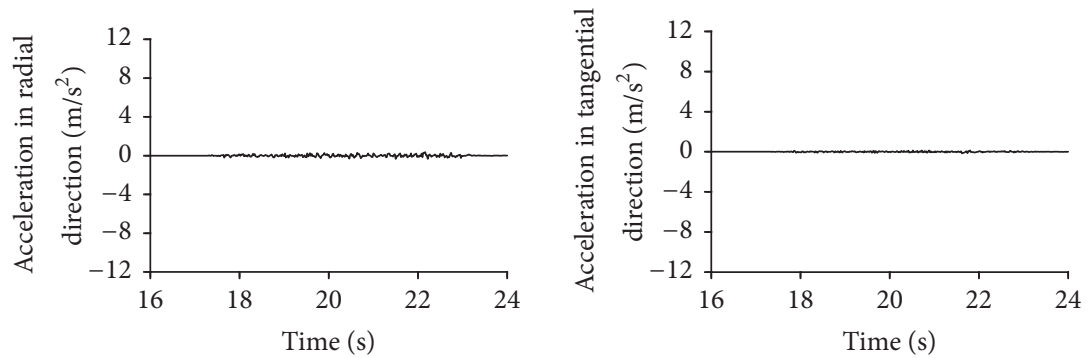

(b)
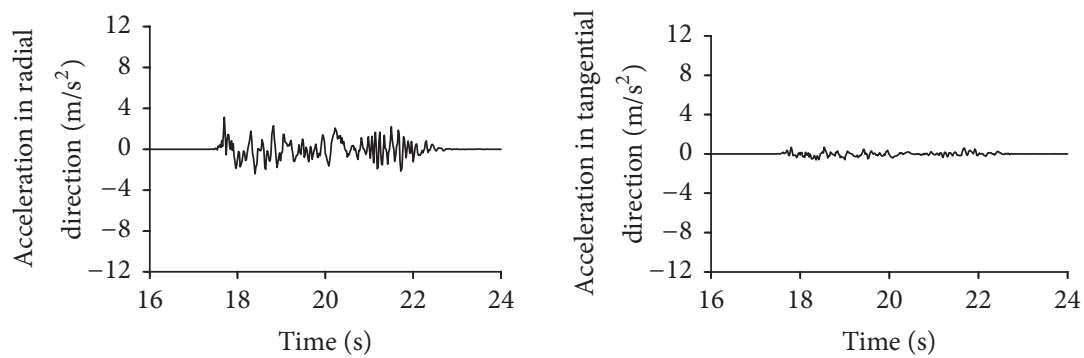
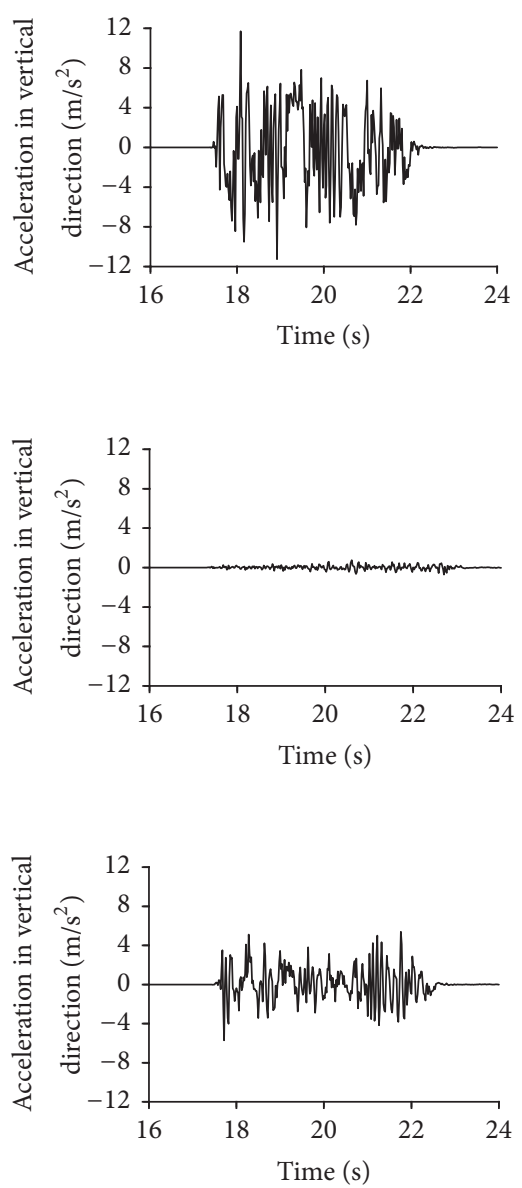

(c)

FIGURE 16: Acceleration histories of collapse-induced ground vibration at point $C$ in radial, tangential, and vertical directions at a distance of $300 \mathrm{~m}$ in (a) computational Case 1; (b) computational Case 2; (c) computational Case 3 for cooling tower under earthquake wave RG1.60.

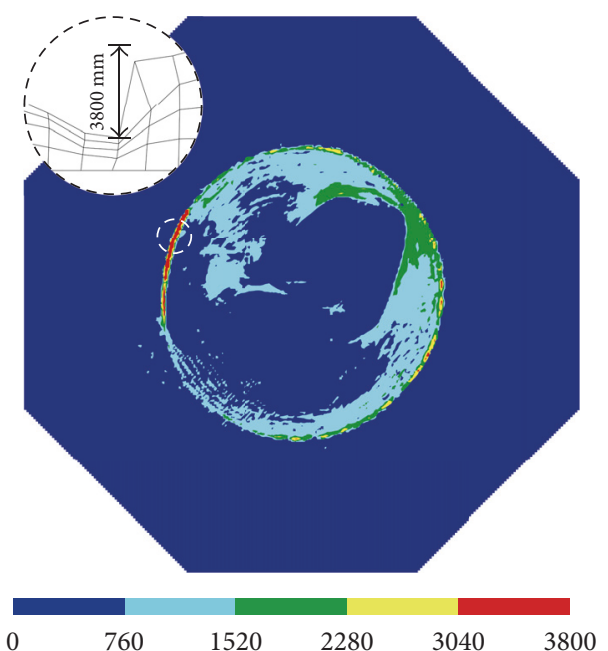

(a)

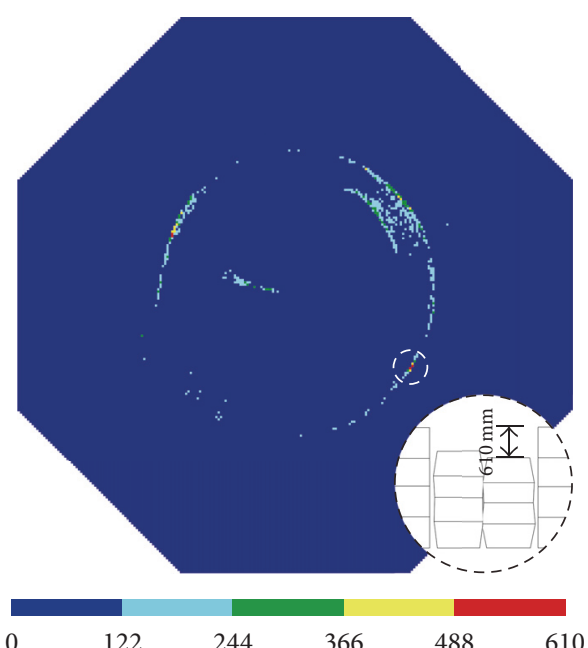

(b)

FIGURE 17: Distribution of compaction heights of cushions in (a) computational Case 2 and (b) computational Case 3 for cooling tower under earthquake wave RG1.60. 


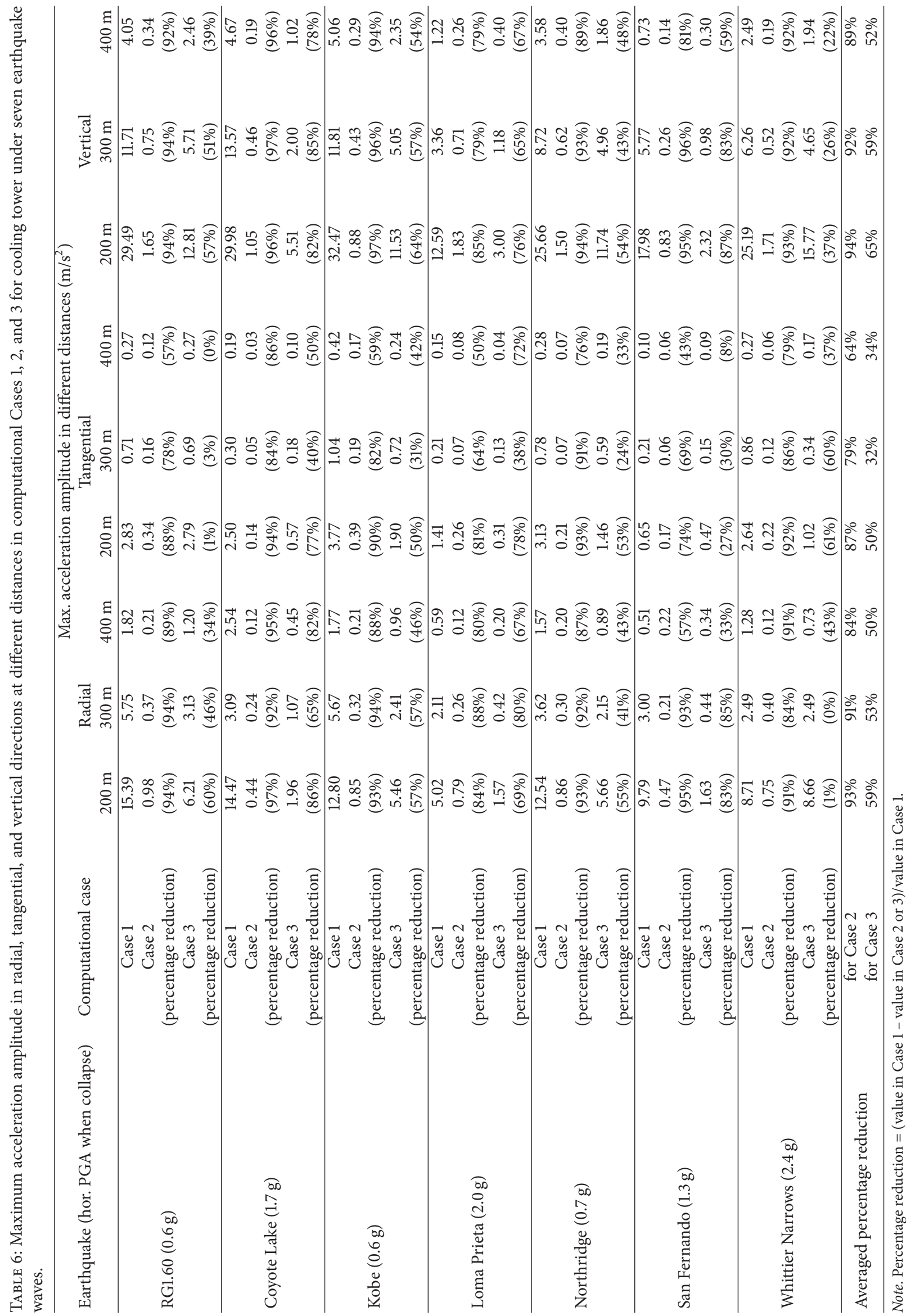




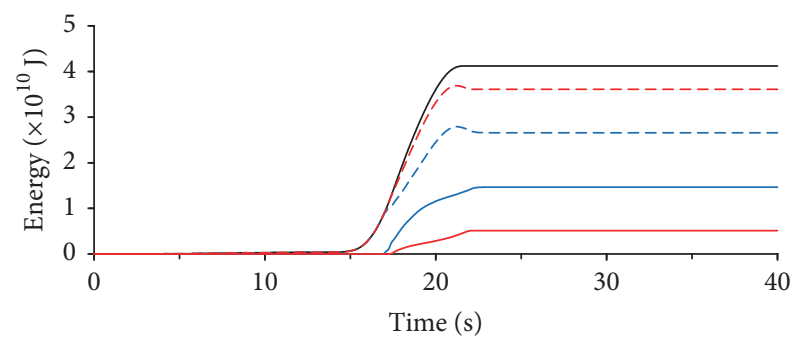

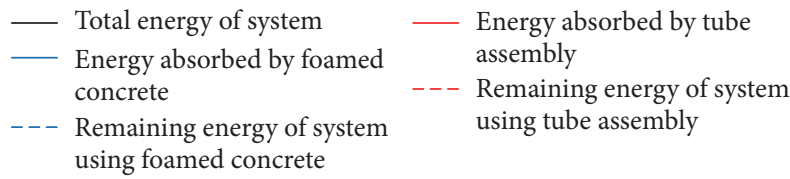

Figure 18: Development histories of total energy of the "cooling tower-cushion-soil" system, energy absorbed by cushions, and remaining energy of the system under earthquake wave RG1.60.

absorption capacities of the two cushions were different. Figure 18 illustrates the development histories of the total energy of the "cooling tower-cushion-soil" system, energy absorbed by each cushion, and the remaining energy of the system under the earthquake wave RG1.60. Results revealed that, in the concerned cases, foamed concrete had a higher energy absorption capacity and a less remaining energy than the "tube assembly" did, resulting in a more significant vibration reduction.

The cushion heights of $4 \mathrm{~m}$ for foamed concrete and $2.4 \mathrm{~m}$ for the "tube assembly" were chosen with consideration of the possible heights of cushions used in practice, available experimental data, and compaction heights impacted by fallen shell fragments. The height of the "tube assembly" was also in conformity with the geometrical parameters of tubes used in previous studies [15], that is, ratios of height to diameter and diameter to thickness. Variation of the geometrical parameters probably led to failure modes rather than concertina failure mode adopted in this study and, therefore, these geometrical parameters were not changed.

The effect of ground vibration reduction using foamed concrete was compared with that using other methods. In [4], a "soft" soil (clay) with a depth of $5 \mathrm{~m}$ acting as overlying soil above rock, an active isolation trench with a depth of $20 \mathrm{~m}$, and a passive isolation trench with a depth of $20 \mathrm{~m}$ were used to reduce collapse-induced vibration, respectively. The maximum acceleration amplitudes were reduced in a range of $28 \%-54 \%, 39 \%-57 \%$, and $12 \%-32 \%$ at a point with a distance of $350 \mathrm{~m}$, respectively. Generally speaking, for onetime impact-induced ground vibration, the effect of vibration reduction using foamed concrete is more efficient than those using methods of overlying "soft" soil and isolation trenches.

\section{Conclusions}

A numerical study was performed to investigate the mitigation of collapse-induced ground vibration using two materials acting as cushions, that is, foamed concrete and the "tube assembly" to enhance the resilience of the "cooling towersoil-containment" system against the postearthquake disaster in NPPs. These two materials have high energy dissipation capacity and, however, were not found to be used in the field of vibration control. This study demonstrates the enormous potential of the two materials in vibration reduction using seven earthquake waves. For foamed concrete with a height of $4 \mathrm{~m}$, collapse-induced ground vibration at the point at a distance of $300 \mathrm{~m}$ was reduced by $91 \%, 79 \%$, and $92 \%$ in radial, tangential, and vertical directions. These values were $53 \%, 32 \%$, and $59 \%$ for the "tube assembly" with a height of $2.4 \mathrm{~m}$. Clearly, a remarkable effect of vibration mitigation was achieved. In the concerned cases, foamed concrete was more efficient than the "tube assembly" and other methods, for example, using overlying "soft" soil and isolation trenches in the previous studies.

An optimization approach is possible, for example, in terms of material properties and height of each cushion. This approach was not performed in this study and will be addressed in future research.

\section{Conflicts of Interest}

The authors declare that they have no conflicts of interest.

\section{Acknowledgments}

The authors would like to acknowledge financial support from the National Natural Science Foundation of China (Grant no. 51578399).

\section{References}

[1] World Nuclear Association, Nuclear Power, http://www.worldnuclear.org/information-library/country-profiles/countries-a-f/ china-nuclear-power.aspx.

[2] F. Lin, H. Ji, Y. Li, Z. Zuo, X. Gu, and Y. Li, "Prediction of ground motion due to the collapse of a large-scale cooling tower under strong earthquakes," Soil Dynamics and Earthquake Engineering, vol. 65, pp. 43-54, 2014.

[3] D. Busch, R. Harte, W. B. Krätzig, and U. Montag, "New natural draft cooling tower of $200 \mathrm{~m}$ of height," Engineering Structures, vol. 24, no. 12, pp. 1509-1521, 2002.

[4] F. Lin, H. Ji, X. Gu, Y. Li, M. Wang, and T. Lin, "NPP planning based on analysis of ground vibration caused by collapse of large-scale cooling towers," Nuclear Engineering and Design, vol. 295, pp. 27-39, 2015.

[5] National Nuclear Safety Administration, General safety principles for design of nuclear power plants (HAD102/01), China Legal Publishing House, Beijing, China, 1989.

[6] International Atomic Energy Agency (IAEA), Seismic design and qualification for nuclear power plants: safety guide, Safety Standards Series No. NS-G-1.6, Vienna, Austria, 2003.

[7] G. Pflanz, K. Hashimoto, and N. Chouw, "Reduction of structural vibrations induced by a moving load," Journal of Applied Mechanics, vol. 5, pp. 555-563, 2002.

[8] F. Lin, Y. Li, X. Gu, X. Zhao, and D. Tang, "Prediction of ground vibration due to the collapse of a $235 \mathrm{~m}$ high cooling tower under accidental loads," Nuclear Engineering and Design, vol. 258, pp. 89-101, 2013. 
[9] M. Srbulov, "Ground vibration engineering: Simplified analyses with case studies and examples," Geotechnical, Geological and Earthquake Engineering, vol. 12, pp. 1-230, 2010.

[10] G. P. Wilson, H. J. Saurenman, and J. T. Nelson, "Control of ground-borne noise and vibration," Journal of Sound and Vibration, vol. 87, no. 2, pp. 339-350, 1983.

[11] C.-M. Kuo, C.-H. Huang, and Y.-Y. Chen, "Vibration characteristics of floating slab track," Journal of Sound and Vibration, vol. 317, no. 3-5, pp. 1017-1034, 2008.

[12] A. Q. Bhatti, "Falling-weight impact response for prototype RC type rock-shed with sand cushion," Materials and Structures/Materiaux et Constructions, vol. 48, no. 10, pp. 3367-3375, 2015.

[13] J. Sun, Z. Chu, Y. Liu, W. Luo, and M. Wang, "Performance of Used Tire Cushion Layer under Rockfall Impact," Shock and Vibration, vol. 2016, Article ID 8760592, 2016.

[14] H. Guo, W. Guo, and Y. Shi, "Computational modeling of the mechanical response of lightweight foamed concrete over a wide range of temperatures and strain rates," Construction and Building Materials, vol. 96, pp. 622-631, 2015.

[15] X. Zhang, H. Zhang, and Z. Wen, "Axial crushing of tapered circular tubes with graded thickness," International Journal of Mechanical Sciences, vol. 92, pp. 12-23, 2015.

[16] U.S. Atomic Energy Commission, Design Response Spectra for Seismic Design of Nuclear Plants (Regulatory Guide 1. 60), Washington, D.C., 1974.

[17] Z.-X. Yang, "Controlled blasting scheme for reinforced concrete chimney," Department of Controlled Blasting of PLA University of Science and Technology, Nanjing, China, 2014.

[18] W. Jiang and F. Lin, "Numerical simulation on ground vibration caused by the demolition of a $200 \mathrm{~m}$ high chimney," in Vibroengineering PROCEDIA, pp. 288-292, LVE International LTD., Kaunas, Lithuania, 2016.

[19] Z. Q. Zhang, J. L. Yang, and Q. M. Li, "An analytical model of foamed concrete aircraft arresting system," International Journal of Impact Engineering, vol. 61, pp. 1-12, 2013.

[20] R. F. Cook, “Soft-ground aircraft arresting systems," Tech. Rep. FAA/PM-87e27, Federal Aviation Administration, Washington, D.C., USA, 1987.

[21] J. C. White and S. K. Agrawal, "Soft ground arresting system for airports," Tech. Rep. CT-93-80, Federal Aviation Administration, Washington, D.C., USA, 1993.

[22] A. Pugsley and M. Macaulay, "The large-scale crumpling of thin cylindrical columns," The Quarterly Journal of Mechanics and Applied Mathematics, vol. 13, pp. 1-9, 1960.

[23] K. R. F. Andrews, G. L. England, and E. Ghani, "Classification of the axial collapse of cylindrical tubes under quasi-static loading," International Journal of Mechanical Sciences, vol. 25, no. 9-10, pp. 687-696, 1983.

[24] J. O. Hallquist Livermore Software Technology Corporation, Livermore, Calif, USA, 2006.

[25] Y. H. Mugahed Amran, N. Farzadnia, and A. A. Abang Ali, "Properties and applications of foamed concrete; a review," Construction \& Building Materials, vol. 101, pp. 990-1005, 2015.

[26] Northeast Electric Power Design Institute Co., Ltd. of China Power Engineering Consulting Group, Study report on air cooling system and turbine of Jidong Nuclear Power Station. Changchun, China, 2016.

[27] M. Avalle, G. Belingardi, and A. Ibba, "Mechanical models of cellular solids: Parameters identification from experimental tests," International Journal of Impact Engineering, vol. 34, no. 1, pp. 3-27, 2007.
[28] Standardization Administration of the People's Republic of China, Code for seismic design of nuclear power plants (GB 50267-97), China Planning Press, Beijing, China, 1998.

[29] F. Lin and Y. Zhang, "An impulse-based model for impact between two concrete blocks," International Journal of Impact Engineering, vol. 107, pp. 96-107, 2017.

[30] E. Kausel and G. Manolis, Wave Motion in Earthquake Engineering, WIT Press, Boston, USA, 2000.

[31] The Pacific Earthquake Engineering Research Center, http:// ngawest2.berkeley.edu/T, 2017.

[32] X. Gu, Q. Yu, Y. Li, and F. Lin, "Collapse process analysis of reinforced concrete super-large cooling towers induced by failure of columns," Journal of Performance of Constructed Facilities, vol. 31, no. 5, 2017.

[33] Q.-Q. Yu, X.-L. Gu, Y. Li, and F. Lin, "Collapse-resistant performance of super-large cooling towers subjected to seismic actions," Engineering Structures, vol. 108, pp. 77-89, 2016. 


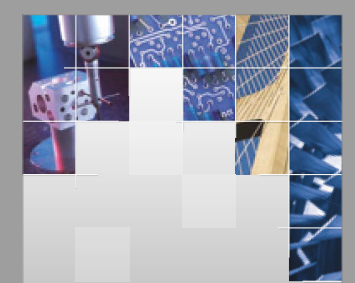

\section{Enfincering}
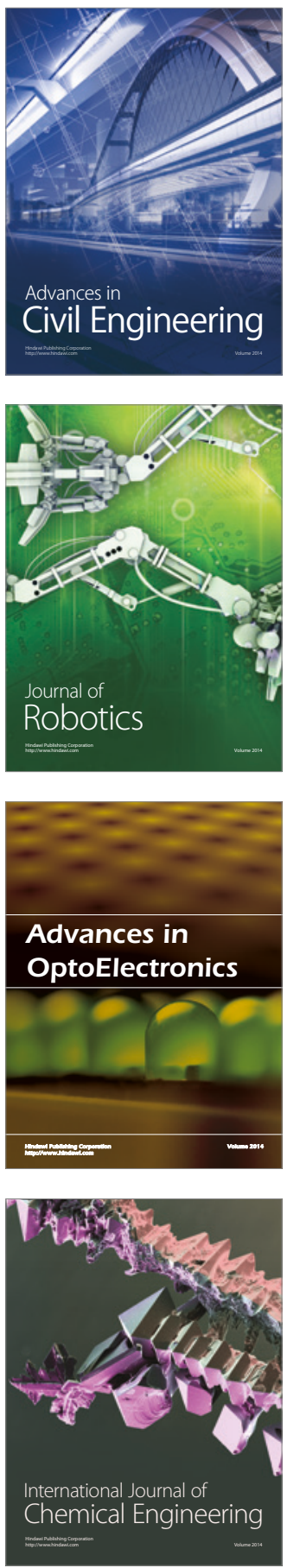

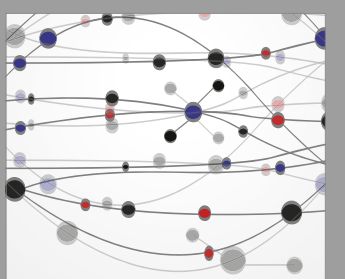

The Scientific World Journal

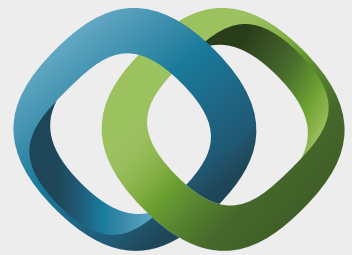

\section{Hindawi}

Submit your manuscripts at

https://www.hindawi.com
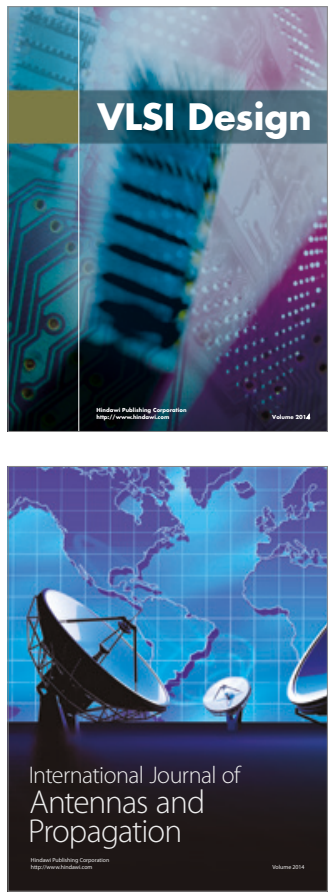

\section{Rotating}

Machinery
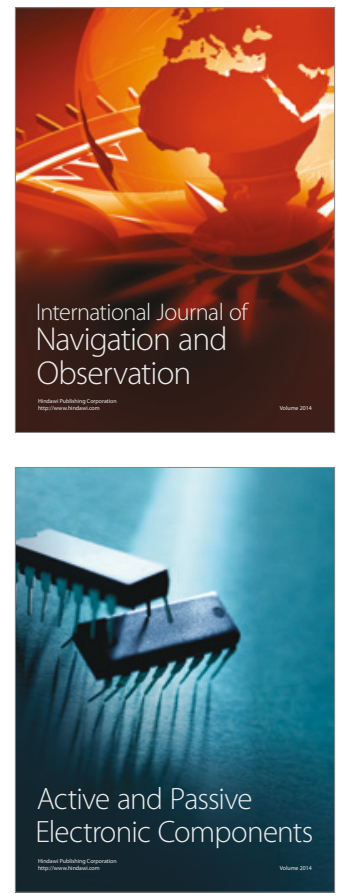
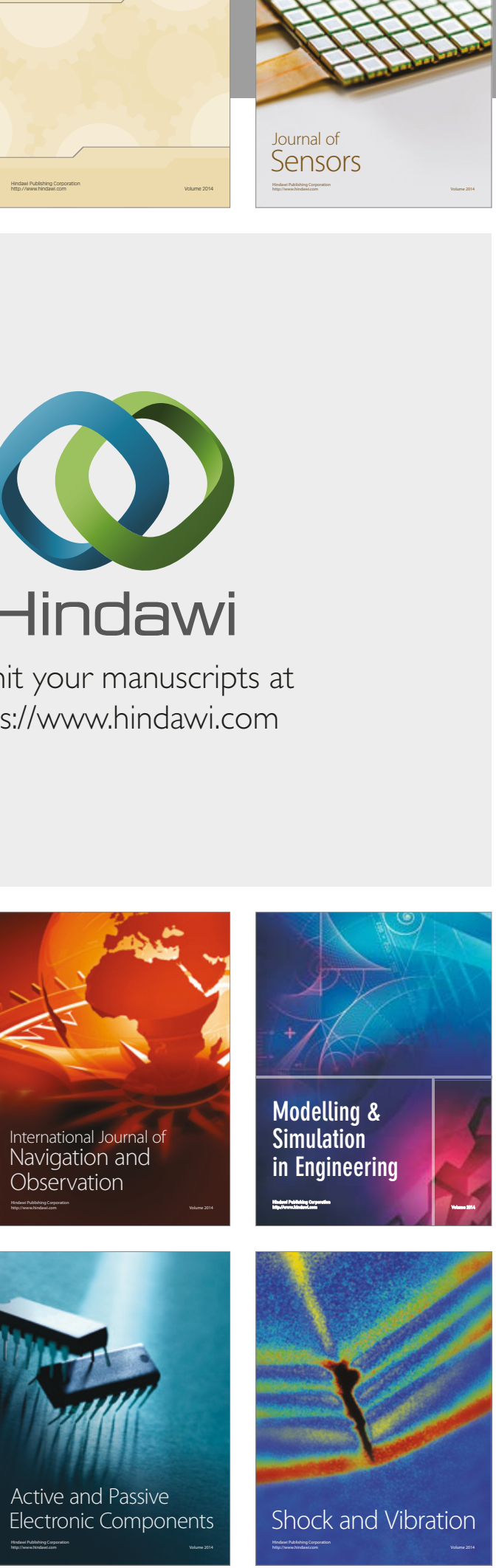
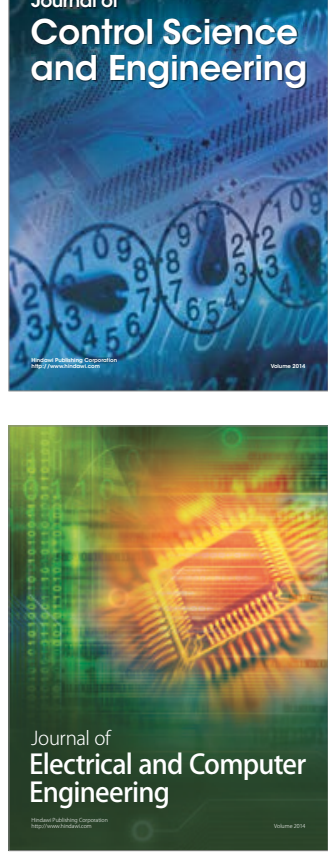

Distributed

Journal of

Control Science

and Engineering
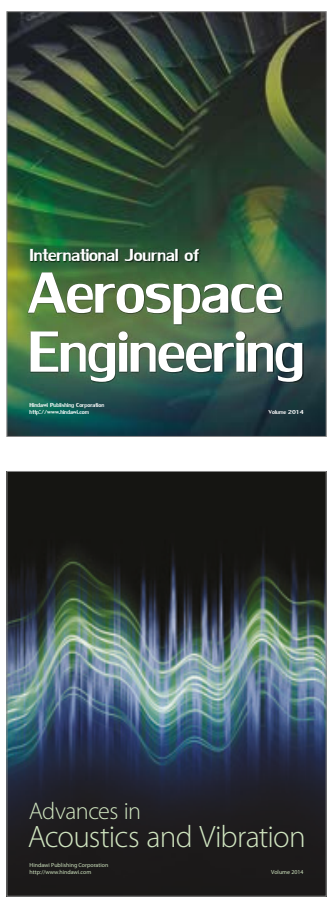

Sensor Networks 